\title{
Evaluación de Lactobacillus plantarum en intestino grueso de lechones por microscopía electrónica y química sanguínea
}

\section{Evaluation of Lactobacillus plantarum in large intestine of piglets by transmission microscopy and blood chemistry}

Henry Jurado G, ${ }^{1 *}$ Ph.D, Diana Castaño Z, ${ }^{2}$ Bacteriol, Cristina Ramírez T, ${ }^{3}$ Ph.D.

\begin{abstract}
${ }^{1}$ Universidad de Nariño, Facultad de Ciencias Pecuarias, Departamento de Producción y Procesamiento Animal, Programa de Zootecnia. Pasto, Colombia. ${ }^{2}$ Institución Universitaria Colegio Mayor de Antioquia, ${ }^{3}$ Universidad del Valle, Escuela de Ingeniería de Alimentos, Grupo de Investigación en Microbiología y Biotecnología Aplicada y Grupo de Investigación en Ingeniería de los Procesos Agroalimentarios y Biotecnológicos GIPAB. Cali, Colombia. *Correspondencia: henryjugam@gmail.com
\end{abstract}

Recibido: Marzo de 2010; Aceptado: Enero de 2011.

\section{RESUMEN}

Objetivo. Evaluar la presencia de Lactobacillus plantarum en intestino grueso de lechones. Materiales y métodos. 50 lechones fueron asignados al azar a 5 tratamientos $(n=10)$. (T0: sin probiótico; T1: con L. plantarum $1 \mathrm{H} 1$; T2: con L. plantarum $1 \mathrm{H} 2$; T3: con probiótico comercial; T4: sin probiótico comercial). Después de los tratamientos, 3 lechones de cada grupo fueron seleccionados aleatoriamente para obtener muestras de intestino grueso para análisis por microscopía electrónica y suero para química sanguínea. La inmunoglobulina A (IgA) se hizo por turbidimetría; colesterol total y nitrógeno ureico (BUN) por espectofotometría. El recuento diferencial de leucocitos y polimorfonucleares (PMN) neutrófilos mediante extendido de sangre. Resultados. Se comprobó la adhesión de L. plantarum $1 \mathrm{H} 1$ y y L. plantarum $1 \mathrm{H} 2$ en el intestino grueso. Se observó secreción de mucina y en la lámina propia inflamación y edema del tejido conectivo. La IgA mostró concentraciones altas en T2 (L. plantarum $1 \mathrm{H} 1$ ) con $333 \mathrm{mg} / 100 \mathrm{~mL}$ y T3 (L. plantarum $1 \mathrm{H} 2$ ) con $300 \mathrm{mg} / 100 \mathrm{~mL}$. Los valores en T3 y T2 en los polimorfonucleares neutrófilos fueron elevados (65\% y 55\% respectivamente). El colesterol total fue menor en T2 y T3 con valores de 113.83 y 93.8 mg\% respectivamente. El BUN para T2 y T3 fue el más bajo con 7.83 y 8.76 mg\% respectivamente. Conclusiones. La utilización de probióticos con $L$. plantarum 1 adicionado en la ración mostró un efecto positivo en la colonización y adhesión en el intestino grueso, así como, una respuesta positiva en su sistema inmune.

Palabras clave: Inmunoglobulinas, Lactobacillus plantarum, lechón, probióticos, sistema inmunológico. (Fuentes: AIMS, CAB, DeSC). 


\section{ABSTRACT}

Objective. To evaluate the presence of Lactobacillus plantarum in large intestine of piglets. Materials and methods. Fifty piglets were randomly allocated into $5(n=10)$ treatment groups (T0: without probiotics; T1: with L. plantarum $1 \mathrm{H} 1$; T2: with L. plantarum $1 \mathrm{H} 2$; T3: with commercial probiotics; T4:without commercial probiotics). After treatment, 3 piglets, from each group, were randomly selected and large intestine samples were taken and analyzed by transmission electron microscopy and serum for blood chemistry. The determination of immunoglobulin $A(\operatorname{IgA})$ was made by turbidimetric method; and the total cholesterol and blood ureic nitrogen (BUN) by espectrophotometry. The differential leukocyte count and polymorphonuclear neutrophils (PMN) was examined in blood smears. Results. Adhesion of $L$. plantarum $1 \mathrm{H} 1$ and $L$. plantarum $1 \mathrm{H} 2$ was found in the mucosa of the large piglet intestine. Was observed secretion of mucin, and inflammation in the lamina propria and connective tissue edema as part of the immune response. IgA showed high concentrations in T2 (L. plantarum $1 \mathrm{H} 1,333 \mathrm{mg} / 100 \mathrm{ML}$ ) and T3 (L. plantarum $1 \mathrm{H} 2,300$ $\mathrm{mg} / 100 \mathrm{~mL}$ ). The T2 and T3 values in polymorphonuclear neutrophils were elevated (65\% and $55 \%$ respectively). Total cholesterol was lower in T2 $(113.83 \%)$ and T3 $(93.8 \%)$. T2 and T3 showed the lowest BUN values ( 7.83 and $8.76 \mathrm{mg} \%$ respectively). Conclusions. The use of probiotics with $L$. plantarum 1 added in the ration showed a positive effect in the colonization and adhesion in the large intestine, as well as, a positive response in their immune system.

Key words: Immunoglobulins, immune system, Lactobacillus plantarum, piglet, probiotics. (Sources: AIMS, CAB, DeSC).

\section{INTRODUCCIÓN}

Los experimentos en modelos animales como en lechones en fase de precebo, indican que la microflora intestinal supone una gran cantidad de microorganismos, como las bacterias probióticas con beneficios para el sistema inmune, como lo es la respuesta inmunitaria de la mucosa (1).

Isolauri et al (2) sostienen que la prevención contra la colonización de patógenos en el tracto gastrointestinal se da por la "exclusión competitiva", a nivel del intestino delgado y grueso sin sufrir pérdidas en su viabilidad. Además, sintetizan compuestos inhibitorios por parte de estos microorganismos (3).

Pathmakanthan et al (4) afirman que Lactobacillus plantarum es capaz de promover la síntesis y secreción de citocina antiinflamatoria IL-10 en los macrófagos y células T que proceden del colon inflamado. La flora endógena intestinal sintetiza los polisacáridos capsulares zwitteriónicos (PSZ), los cuales, emplean el sistema de presentación del complejo mayor de histocompatibilidad II (MHC) para activar las células $T$ mediante su reconocimiento por las proteínas receptoras alfa/beta de dichas células $T$ (5). Así, por ejemplo, células T CD4+ humanas estimuladas por estas moléculas in vitro y transferidas a ratas in vivo protegen contra abscesos intraabdominales provocados con un estímulo bacteriano viable.

El peptidoglicano de bacterias grampositivas estimula las proteínas NOD, (receptores específicos citoplasmáticos) y caracterizados por presentar repeticiones ricas en leucina (LRR).

Los receptores NOD1 y NOD2 pueden estimular el factor de transcripción NFKB. La presencia de regiones activadoras de caspasa en proteínas NOD es importante en la apoptosis (6).

Lactobacillus plantarum se ha utilizado en cerdos para el control de bacterias entéricas (7), motivo por el cual este estudio, pretendió evaluar la adhesión de 
Lactobacillus plantarum en el intestino grueso de lechones en fase de precebo mediante microscopía electrónica de transmisión y química sanguínea.

\section{MATERIALES Y MÉTODOS}

Sitio de estudio. El presente estudio se realizó en el Laboratorio de Microscopía Electrónica de la Universidad del Cauca (Popayán, Cauca), en el Laboratorio de Bacteriología Especializado para Diagnóstico Veterinario de la ciudad de Cali y en la finca "La Sierra", (Villa Gorgona, Candelaria, Colombia).

Toma de muestras. Se trabajó con un total de 50 lechones, distribuidos en cinco tratamientos, 10 lechones por tratamiento. Se evaluaron 3 lechones por tratamiento al final de la fase de precebo (sexta semana), provenientes de: T0 (Control) sin adición de probiótico ni antibiótico, únicamente con concentrado de iniciación; T1: $L$. plantarum $1 \mathrm{H} 1$, junto con el concentrado de iniciación; T2: L. plantarum $1 \mathrm{H} 2$, junto con el concentrado de iniciación; T3: probiótico comercial, junto con el concentrado de iniciación; T4: Sin adición de probiótico. Se usó el concentrado de preiniciación e iniciación con antibiótico.

Los resultados de las diferentes mediciones fueron reportados como promedio para cada uno de los tratamientos evaluados.

\section{Obtención y procesamiento de las} muestras para microscopía electrónica. Se realizaron cortes de aproximadamente $1 \mathrm{~cm}$ de largo y $1 \mathrm{~cm}$ de ancho del colon del intestino grueso y fijadas en glutaraldehído al $2.5 \%$. Posteriormente, fueron refrigeradas y transportadas al laboratorio de microscopía electrónica.

De las muestras se tomaron secciones más pequeñas, que fueron lavadas tres veces por 5 minutos cada una con Fosfato de Milloniq. Se fijaron con tetróxido de osmio al $2 \%$ por una hora; y lavadas tres veces por 5 minutos cada una con fosfato de Milloniq.
Posteriormente, fueron sometidas a un proceso de deshidratación por 15 min para cada una con alcohol así: alcohol de 30\%; 50\%; 70\%; 80\%；90\%; 95\%; 100\%. La deshidratación continuó con mezclas de etanol-oxido de propileno en relaciones: $3: 1 ; 1: 1 ; 1: 3$ (20 min cada una), óxido de propileno puro (20 $\mathrm{min}$ ); óxido de propileno puro (20 min).

Durante el proceso de preimbibición se utilizó una mezcla de óxido de propileno: resina Polybed relación 3:1 (2 horas); 1:1 (2 horas); 1:3 (2 horas). Enseguida el proceso de imbibición con resina pura (toda la noche) en nevera, y se polimerizaron en horno a $65^{\circ} \mathrm{C}$ (48 horas).

Polimerizadas las muestras, en ultramicrótomo (Leica modelo UCT), se sacaron cortes semifinos de $1 \mu \mathrm{m}$ de grosor para ser observadas en Microscopía Óptica de Alta Resolución (MOAR) marca NIKON (Eclipse 80i, Nikon Instruments Inc. USA), se tiñieron con azul de toluidina (en portaobjetos). La captura de las imágenes se hizo con el sistema de captura y análisis de imágenes NIS-Elements $F$ 2.30, la cámara utilizada fue NIKON DIGITAL SIGHT DS-2Mv.

Para el estudio por Microscopía Electrónica de Transmisión (TEM) marca JEOL (JEM $1200 \mathrm{EX})$, se utilizaron cortes de $90 \mathrm{~nm}$ de grosor (ultramicrótomo), recogidos en rejillas de Niquel o cobre, contrastados con acetato de uranilo y citrato de plomo. Las fotos fueron tomadas en películas Kodak especiales para Microscopia Electrónica. El proceso de revelado de los negativos es el utilizado para blanco y negro con revelador y fijador Kodak (4-5 minutos en revelador, 30 segundos en agua y 10 minutos en fijador, lavado con agua corriente por media hora).

Luego los negativos fueron escaneados en un Scanner para negativos marca Epson (Epson perfection 4490 Photo).

Análisis de química sanguínea. La obtención de la muestra de sangre se hizo con tubos al vacío con anticoagulante EDTA, haciendo una ligera presión longitudinal en 
la oreja para conseguir un mayor flujo de sangre. Posteriormente con una lanceta estéril se efectuó la punción. Se descartó la primera gota para el llenado de las pipetas requeridas. Se mezcló la sangre en el tubo por inversión varias veces, para una muestra homogénea.

El análisis de sangre se hizo por el método de los dos portaobjetos, colocando una pequeña gota de sangre sobre un portaobjetos a $2 \mathrm{~cm}$ aproximadamente de unos de sus extremos. Se colocó el canto de otro portaobjetos por la parte anterior a la gota de sangre, formando un ángulo aproximadamente de $45^{\circ}$ y desplazándolo suavemente hasta que alcance la gota de sangre. Se esperó a que por capilaridad toda la sangre se distribuya uniformemente y posteriormente se deslizó suavemente un portaobjetos sobre el otro, hasta que la gota de sangre quede bien extendida. Se dejó secar el frotis al aire y se coloreó con Tinción de Wright.

Inmunoglobulina A (IgA). Se determinó mediante la técnica de Turbidimetría.

BUN. Se realizó por medio de un espectrofotómetro. El parámetro medido se transformó en úrea multiplicando por $2.14 \mathrm{y}$ ésta en BUN por 0.467. La muestra de sangre se centrífugó a 1500 rpm (10 minutos) para obtener el suero. Valores de referencia del BUN: 5-25 mg/dL (8).

Colesterol total. La muestra se centrifugó 10 min a 1500 r.p.m. para obtener suero. Tanto el colesterol libre como los esterificados presentes en la muestra, originaron un complejo coloreado cuantificado por espectrofotometría.

La muestra con el reactivo de color se mezclaron e incubaron a temperatura ambiente (10 min). Se leyó la absorbancia $(A=500 \mathrm{~nm})$ del patrón y la muestra frente al blanco de reactivo.

Cálculo: A Muestra x C Patrón = C Muestra A Patrón

Valores de referencia: Hasta 200 mg/dL (9).

Para las mediciones de colesterol se acepta un $\%$ de inexactitud $\pm 5 \%$ y un $\mathrm{CV} \pm 5 \%$ y otros laboratorios aconsejan que debe ser reducidas $a \pm 3 \%$ (10).
Recuento de glóbulos blancos. Se realizó con hematocitómetro y microscopio óptico. Se mezclaron $10 \mu \mathrm{L}$ de la muestra anticoagulada con EDTA y $190 \mu \mathrm{L}$ de ácido acético al 3\%. Se leyó en objetivo de 40X. Posteriormente, el total de células se multiplicaron por el factor 50 obtenido de dividir el factor de dilución por el volumen total utilizado para el recuento.

Para el recuento diferencial de leucocitos se examinó el extendido de sangre periférica utilizando el objetivo de $10 x$ y con el de 100x el recuento diferencial contando 100 células, observándose la morfología de las células blancas.

\section{RESULTADOS}

Los resultados de la evaluación de epitelio intestinal y adhesión bacteriana de los tratamientos $\mathrm{T} 1$ (L. plantarum $1 \mathrm{H} 1$ ) y $\mathrm{T} 2$ (L. plantarum $1 \mathrm{H} 2$ ), mediante microscopia electrónica de transmisión (TEM), se muestran en dos fases: una corresponde a las características histológicas de la mucosa intestinal y la otra a la adhesión de las bacterias estudiadas en el epitelio del intestino grueso. Las porciones seleccionadas fueron del colon.

La figura 1 muestra el corte longitudinal de una glándula intestinal acompañada de la Lámina propia (LP).

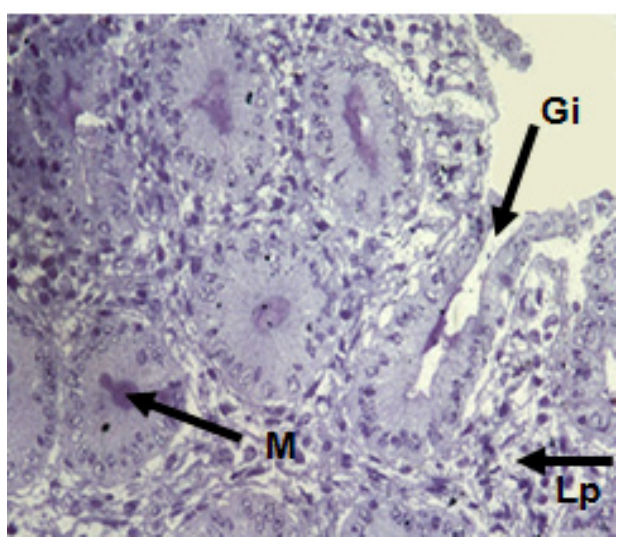

Figura 1. Corte longitudinal de una glándula intestinal (Gi) acompañada de la lámina propia (Lp); que en conjunto forman la mucosa del intestino grueso del cerdo. También se aprecian cortes transversales de las glándulas y en su interior la secreción de mucina (M). Azul de Toloudina. 40x. 
En la figura 2 se observa la mucosa del intestino grueso del cerdo, acompañado de un pequeño grupo de bacterias.

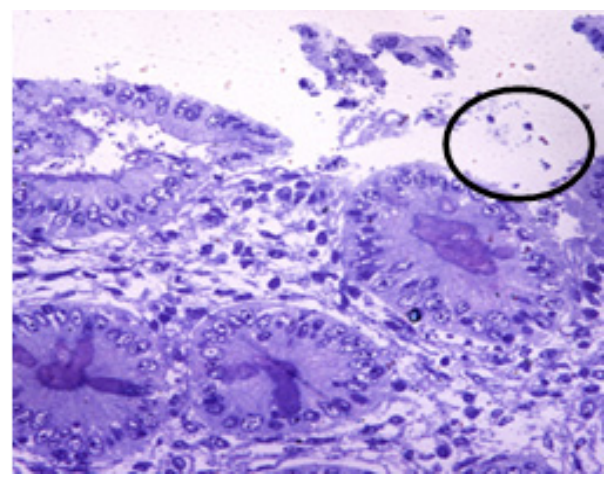

Figura 2. Corte transversal de la mucosa del intestino grueso del cerdo, observándose en la luz ( $L$ ) del órgano un pequeño grupo de bacterias (B). Azul de Toloudina 100x.

En la figura 3 se evidencia el corte transversal de la mucosa intestinal y del infiltrado inflamatorio como respuesta del sistema inmune a un agente extraño.

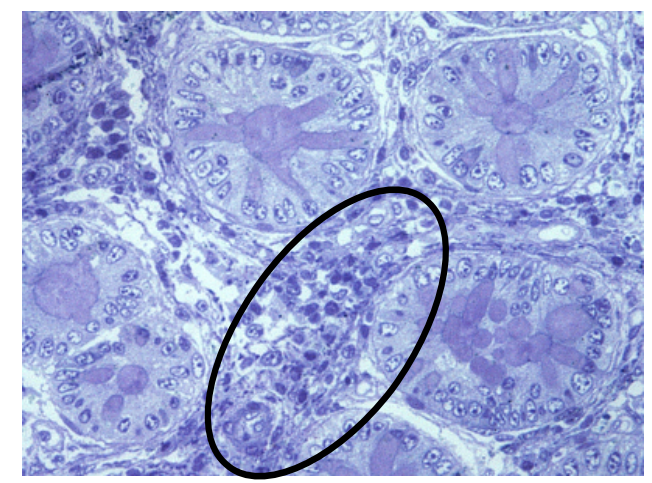

Figura 3. Corte transversal de la mucosa intestinal de cerdo en cuya lámina propia se identifica claramente el infiltrado inflamatorio que se ha formado en respuesta del sistema inmune a un agente extraño. Azul de Toloudina $40 \mathrm{x} x$

En la figura 4 se aprecia una microfotografía electrónica de $L$. plantarum $1 \mathrm{H} 1$ con cápsula presente en la mucosa del intestino grueso del lechón.

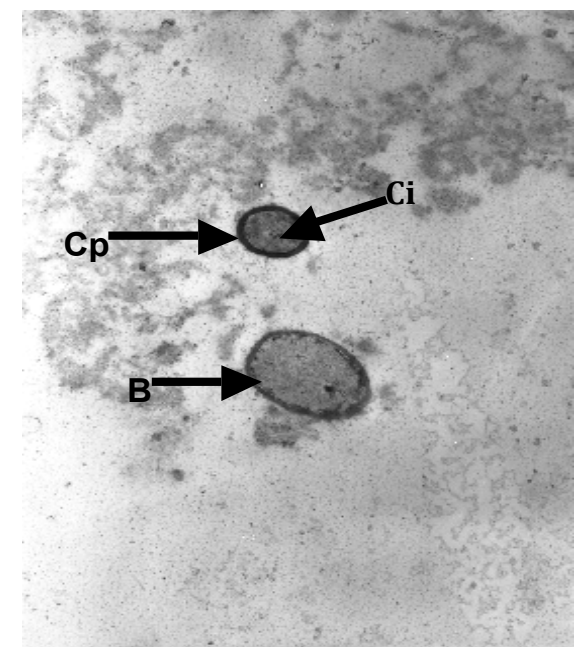

Figura 4. Microfotografía Electrónica de $L$. plantarum $1 \mathrm{H} 1$ (B) presentes en la mucosa del intestino grueso del cerdo. En la bacteria de la parte superior se observa la cápsula de la bacteria (Cp) la cual es muy electrodensa, con su citoplasma (Ci). $500 \mathrm{~nm}$

En la figura 5 se puede ver una microfotografía electrónica de la mucosa del intestino donde se aprecian un conjunto de bacterias de $L$. plantarum $1 \mathrm{H} 2$.

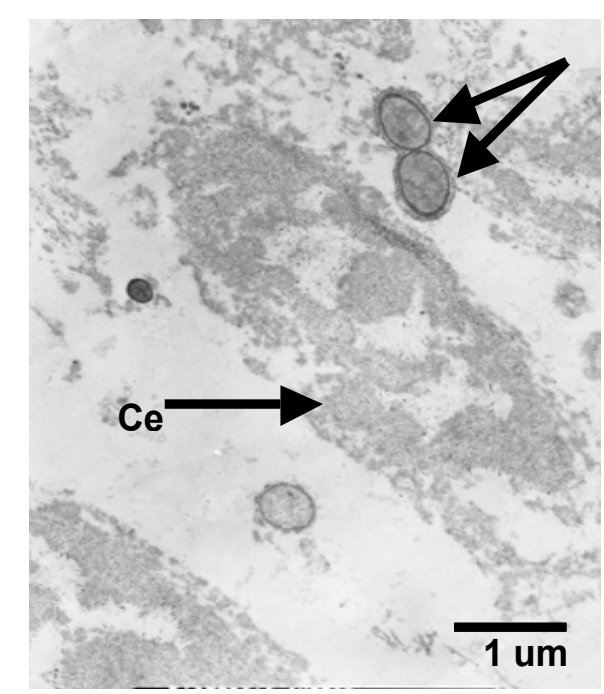

Figura 5. Microfotografía Electrónica de la mucosa del intestino grueso del cerdo. Se observa un grupo de bacterias de $L$. plantarum $1 \mathrm{H} 2$ acompañadas de núcleos de células epiteliales (Ce). 500nm 
En la figura 6 se observan los resultados de la concentración de inmunoglobulina $A$ (IgA) al final del tratamiento (final de la fase de precebo), indicando que los valores más altos se presentaron en T1 ( $L$. plantarum 1 H1), T2 (L. plantarum 1 H2) y T3 (Probiótico comercial), con concentraciones de 333 $\mathrm{mg} / 100 \mathrm{~mL}, 300 \mathrm{mg} / 100 \mathrm{~mL}$ y $300 \mathrm{mg} /$ $100 \mathrm{~mL}$ respectivamente, valores muy superiores a la concentración normal en cerdos que es de $200 \mathrm{mg} / 100 \mathrm{~mL}$.

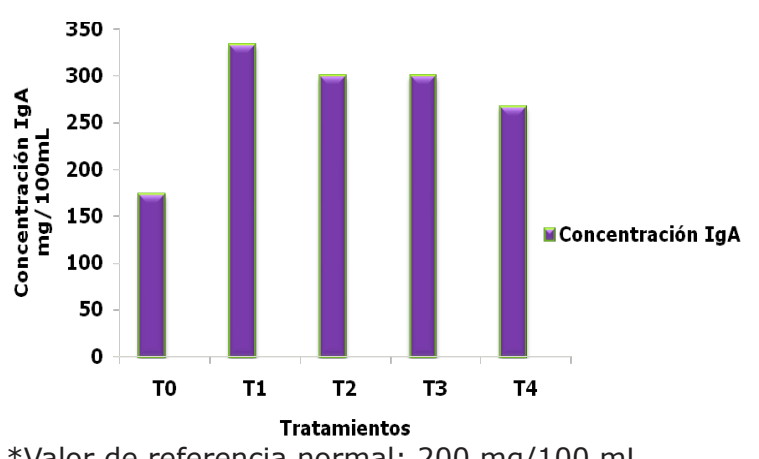

Figura 6. Concentración de inmunoglobulina $A$ $(\operatorname{Ig} A)$ en los lechones en la fase de precebo.

En la figura 7 se aprecia cómo desde el punto de vista inmunológico fue una respuesta positiva al tratamiento efectuado con inóculos probióticos en la ración, por cuanto, produjeron una inmunidad positiva en el tratamiento T2 (Lactobacillus plantarum $1 \mathrm{H} 2$ ) representada en los polimorfonucleares neutrófilos elevados del $65 \%$, y para el caso de T1 (Lactobacillus plantarum $1 \mathrm{H} 1$ ) fue del $55 \%$.

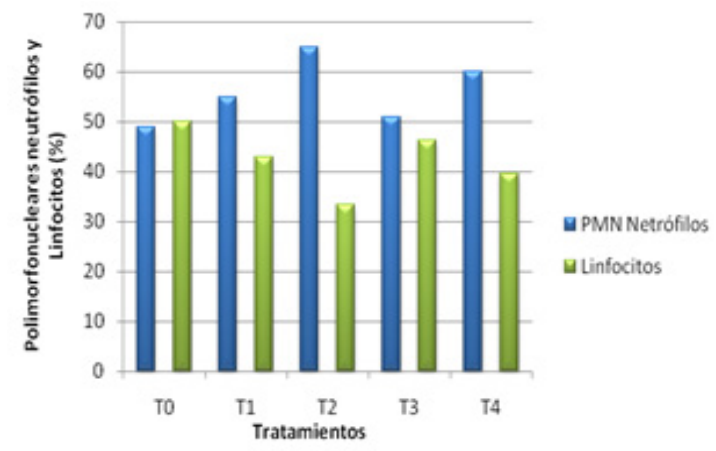

*VN polimorfonuclear neutrófilo: 42 -75 \%

Figura 7. Concentración de polimorfonucleares neutrófilos y linfocitos en los lechones en la fase de precebo.
Con respecto a los linfocitos, se pudo apreciar en la misma Figura 7 una ligera variación en el número de estos como respuesta favorable a los probióticos, lo que significa una mejor inmunidad específica. Esto corrobora la actividad de las cepas utilizadas, según Brizuela (11). En algunos casos, se observó la presencia de linfocitos atípicos que pueden presentarse en una variedad de situaciones, no siendo siempre patológico.

Otros resultados importantes se obtuvieron en los niveles de colesterol total y nitrógeno ureico (BUN) al final del experimento (Figura $8)$. Con respecto a los niveles de colesterol total para el caso de los tratamientos T1 y T2 los valores promedio fueron de 113.83 y $93.8 \mathrm{mg} \%$ respectivamente. Siendo estos valores los más bajos junto con el T4 (97,36 mg\%). Los resultados de nitrógeno ureico (BUN) indicaron que para T1 y T2 los valores promedio fueron de 7.83 y 8.76 mg\% respectivamente. Siendo estos valores los más bajos junto con el T3 (7.2 mg\%).

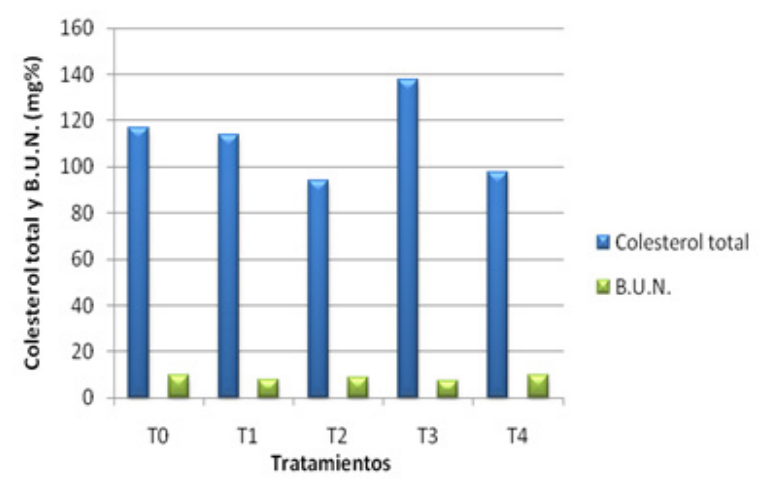

*VN Colesterol: Hasta 220 mg\%, **VN BUN: Hasta $22 \mathrm{mg} \%$

Figura 8. Concentraciones (mg\%) de colesterol total y BUN de los lechones en fase de precebo.

Estos resultados a nivel de química sanguínea indicaron que no había cambios significativos en estos parámetros, puesto que son animales jóvenes con dietas balanceadas.

En la tabla 1 se puede apreciar la viabilidad de los inóculos de $L$. plantarum $1 \mathrm{H} 1$ (T1) y L. plantarum $1 \mathrm{H} 2$ (T2), junto con el concentrado de iniciación elaborado en 
Tabla 1. Viabilidad de los inóculos de $L b$. plantarum $1 \mathrm{H} 1$ (T1) y Lb. plantarum $1 \mathrm{H} 2$ (T2) junto con el concentrado de iniciación elaborado en la finca "La Sierra" comparado con el tratamiento control o testigo (T0) en ciego, colon y recto del intestino grueso de los lechones al final de la fase de precebo.

\begin{tabular}{lcc}
\hline \multicolumn{1}{c}{ Probiótico } & $\begin{array}{c}\text { Porción intestino } \\
\text { grueso }\end{array}$ & UFC/ mL (103) \\
\hline L. plantarum 1 H2 (T2) & Ciego & $2.35 \times 105$ \\
L. plantarum 1 H2 (T2) & Colon transverso & $1.5 \times 105$ \\
L. plantarum 1 H2 (T2) & Recto & $8.0 \times 104$ \\
L. plantarum 1 H1 (T1) & Ciego & $1.0 \times 105$ \\
L. plantarum 1 H1 (T1) & Colon transverso & $1.3 \times 105$ \\
L. plantarum 1 H1 (T1) & Recto & $1.1 \times 105$ \\
Testigo (T0) & Ciego & 0 \\
Testigo (T0) & Colon transverso & 0 \\
Testigo (T0) & Recto & 0 \\
\hline
\end{tabular}

la finca "La Sierra", comparado con el tratamiento control o testigo (TO) en ciego, colon y recto del intestino grueso de los lechones, al final de la fase de precebo.

\section{DISCUSIóN}

El género Lactobacillus, ha sido usado en animales para prevenir desordenes en el tracto gastrointestinal, como es el caso de la diarrea (12-13). Son microorganismos sin capacidad patógena, capaces de prevenir la adherencia y replicación de bacterias patógenas (14).

El tracto gastrointestinal, es la superficie del cuerpo en continuo contacto con el medio externo; posee mecanismos para prevenir la entrada de microorganismos y compuestos patógenos al animal. Así, la monocapa epitelial y el revestimiento de moco que la recubre, junto con las uniones estrechas que mantienen unidos a los enterocitos, forma una barrera física que previene la entrada a la lámina propia de patógenos y antígenos luminales. Por otro lado, la inmunoglobulina ( $\operatorname{IgA}$ ) secretada por el intestino, bloquea la unión de patógenos al epitelio, evitando su acceso a la lámina propia intestinal, y además, aglutina bacterias y virus que son atrapados en la barrera de moco y eliminados en las heces (14).
Mare et al (15), investigaron qué porción del intestino de lechones lactantes y en precebo podrían ser colonizados por $L$. plantarum 423 y L. salivarius 241 en un modelo gastrointestinal. Se utilizó una técnica de hibridación in situ fluorescente (FISH). Así, determinaron que L. plantarum 423 se adhería al íleon y colon posterior y $L$. salivarius 241 al duodeno en los lechones lactantes. La cepa 241 se adhirió al duodeno y colon posterior de los lechones en precebo, mientras que la cepa 423 se localizó en el íleon. Además, sostienen que L. plantarum 423 y L. salivarius 241 se adhieren al tracto intestinal, dependiendo de su edad. Estos resultados coinciden con $L$. salivarius en el sitio de adhesión de $L$. plantarum $1 \mathrm{H} 1$ y L. plantarum $1 \mathrm{H} 2$ en el colon, y difieren para L. plantarum 423.

El interés por la adhesión y colonización de las BAL, ha hecho de los Lactobacillus efectivos para dirigirse a la mucosa, tal como el tracto gastrointestinal o las vías nasales, para provocar una respuesta inmune deseada contra el antígeno presentante en el animal. Además, poseen ciertas propiedades como: actividad adyuvante, propiedades de adhesión a mucosas (como se pudo apreciar en la presente investigación) y baja inmunogenicidad, intrínseca, y así, se pueden usar en vacunación oral.

El conocimiento de la estructura y del modo de expresión de proteínas relacionadas con la superficie de Lactobacillus y su adherencia a la mucosa y/o a la matriz extracelular es importante para una vacunación efectiva. Los factores de adherencia pueden ser críticos para la apropiada presentación del antígeno con objeto de que cepas recombinantes de BAL provoquen respuestas de IgA en mucosas y/o de IgG en suero al antígeno expresado en un huésped. La inmunización oral es altamente deseable por la facilidad, bajo costo, almacenamiento y administración de la vacuna. Un vehículo u organismo de administración efectivo debe ser uno que esté normalmente presente en el tracto gastrointestinal del organismo hospedador y debe dirigirse con precisión a los sitios mucosales de infección y adherirse a la 
superficie de las mucosas. Los Lactobacillus poseen ambas características. Un vehículo útil de administración vacunal debe, además, ser capaz de expresar antígenos de interés a niveles altos para inmunizar con éxito al huésped y no ser patogénico para el huésped (16). Además, estos Lactobacillus presentan una mayor prevención de transposición bacteriana, y aumento de la secreción de mucina protectora del intestino (17), propiedades de co-agregación y adhesión (18).

Los resultados de las concentraciones de IgA para los tratamientos T1, T2 y T3 (333 $\mathrm{mg} / 100 \mathrm{~mL}, 300 \mathrm{mg} / 100 \mathrm{~mL}$ y $300 \mathrm{mg} / 100$ $\mathrm{mL}$ respectivamente), y son superiores a la concentración normal para los cerdos que es de $200 \mathrm{mg} / 100 \mathrm{~mL}$. Esta IgA actúa junto con la IgM, en la exclusión inmunitaria (19).

Esta IgA se encuentra en saliva y líquido intestinal. Protege las superficies corporales, y así, 90\% de las células que contienen inmunoglobulina en la lámina propia intestinal, presentan IgA (20), siendo sintetizada y secretada por las células plasmáticas de la submucosa intestinal (criptas). Su accionar se da porque esta IgA se une a un receptor glucoproteínico de inmunoglobulina polimérica ( $\mathrm{pIgR}$ ) en la superficie basal de las células del epitelio intestinal; cuando llega a la superficie exterior, la vesícula endocítica se fusiona con la membrana plasmática y expone la IgA a la luz intestinal. Posteriormente, la porción extracelular del pIgR se separa por enzimas proteolíticas, de modo que la IgA, aún con el péptido receptor unido (SIgA) es liberada en la luz. Esto explicaría en parte, los valores altos presentados en los tratamientos con L. plantarum 1 como probióticos suministrados en la ración de iniciación en la fase de precebo, y que permitirían controlar infecciones entéricas, como la diarrea.

Es eficaz contra enzimas virales y bacterianas, además, actúa como opsonina y en algunos sistemas de citotoxidad celular dependiente de anticuerpos. Su mayor contribución se da contra la adhesión bacteriana y viral a las superficies epiteliales (exclusión inmunitaria). De esta manera, por ejemplo, las bacterias patógenas como E. coli, no podrían adherirse a las células epiteliales del intestino, o pueden pasar de largo con el contenido intestinal sin causar ningún daño. También, esta IgA intracelular se caracteriza por excretar antígenos extraños, es decir, se une a antígenos que han penetrado a la submucosa. Una consideración importante es el mantenimiento de la función de barrera intestinal, lo constituye la enfermedad inflamatoria intestinal, en donde la integridad de la barrera epitelial está comprometida, permitiendo el paso de antígenos luminales a la lámina propia, desencadenando una respuesta inmune exagerada y contribuir en la perpetuación de proceso inflamatorio intestinal (21); esto, implicaría que L. plantarum $1 \mathrm{H} 1$ y L. plantarum $1 \mathrm{H} 2$ podrían contribuir muy posiblemente a facilitar la reversión de esta situación y normalizar la permeabilidad intestinal incrementada, mejorando así la respuesta inflamatoria intestinal.

Schultz et al (17) sostienen que en circunstancias normales, la respuesta inmunitaria intestinal a las bacterias residentes se verá limitada por una respuesta inmunitaria supresora (respuesta TH2) con predominio de IgA y de la citocina antiinflamatoria IL-10. Hallazgos recientes han revelado que determinadas células $T$ reguladoras, como las Th3, que producen factor transformador del crecimiento $\beta$ (TGF- $\beta$ ), y las células $\operatorname{Tr} 1$, que producen IL- 10, regulan la respuesta inflamatoria de la mucosa. El déficit de citocinas o tipos celulares conduce a inflamación de la mucosa a causa de la respuesta anormal a la flora endógena intestinal. Se ha observado que los Lactobacillus previenen la aparición de colitis espontánea en los ratones con déficit de interleucina 10 y que la aportación continuada de Lactobacillus plantarum atenúa la inflamación en este modelo.

Es importante tener en cuenta, que entre las células del sistema inmune intestinal, incluyen los linfocitos y eosinófilos y varios tipos de células presentadoras de Ag (CPA), presentes en el tejido conectivo de la lámina propia (LP) intestinal, entre otras. Ciertos 
linfocitos también se encuentran entre las células epiteliales del intestino (linfocitos intraepiteliales o LIE). Además, grupos de nódulos linfoides organizados (placas de Peyer, agregados linfoides), están en el tracto intestinal (22).

Por lo tanto, es importante considerar que la microflora intestinal desempeña un papel fundamental en la salud del hospedero, de ahí la necesidad de su mantenimiento. Por esta razón, la utilización de $L$. plantarum 1 ayudaría a minimizar la presencia de diarreas y promover el crecimiento de cerdos al destete; estimulando la inmunidad protectora contra patógenos, aumentar la respuesta inmune de la mucosa intestinal, fortalecer muy posiblemente los mecanismos inespecíficos de defensa intestinal dados por la barrera mucosal que actúa en conjunción con el sistema inmune local. La información acerca de L. plantarum aún es limitado, y la variabilidad de su efecto puede estar relacionada con diferencias entre cepas y baja viabilidad antigénica. Por ello, el conocimiento del accionar de esta bacteria en el intestino estimulando las células responsables de la inmunidad ayudaría a mejorar su uso como sustancias moduladoras de la respuesta inmune (23). Además, se sugiere que las LAB y los Lactobacillus modulan la función de las células T mediante la modulación de la función de DC (24).

Lim et al (25) y Charalampopoulos et al (20) afirman que la aplicación de los Lactobacillus reducen el colesterol en suero, y detienen la disfunción intestinal; coincidiendo con los resultados encontrados en los tratamientos $\mathrm{T} 1$ y T2.

Investigaciones llevadas a cabo por Haberer et al (26); mostraron que alimentar lechones con dietas elevadas en colesterol y acompañadas con Lactobacillus, y posteriormente alimentarlos con dietas normales, la actividad de la enzima h-glucuronidasa y azoreductasa (indicadoras de actividad procarcinogénica), fue reducida durante cinco semanas de suplementación del probiótico.

Pino y Dihigo (27) investigaron el efecto de probióticos sobre el hígado en cerdos de precebo, con un aumento del peso del hígado a $(p<0.05)$, aumentando en un $30 \%$ con respecto al control; dado por el aumento de su actividad. Resultados significativos con aumento del peso del ciego a $(p<0.001)$, pudiendo estar dado por un aumento de su actividad al tratar a los animales con L. acidophilus.

Se puede inferir, que es necesario la presencia del probiótico, en este estudio, a base de $L$. plantarum 1 en la dieta de forma constante para lograr la acción hipocolesterolémica. Los mecanismos de acción propuestos para lograr esta respuesta de los probióticos pueden ser: i) propician la formación de esteres de colesterol en el intestino favoreciendo su excreción (28), ii) asimilación del compuesto por la bacteria iii) actividad hidrolasa de sales biliares del probiótico (25).

Con respecto a la acción de los probióticos de Lactobacillus plantarum $1 \mathrm{H} 1$ y Lactobacillus plantarum $1 \mathrm{H} 2$ contribuyen a una utilización más eficiente de la dieta y así, posiblemente reducir algunos compuestos tóxicos que se originan de ella. Los valores encontrados en el BUN son muy importantes por cuanto, un incremento por fuera de los límites normales de urea en sangre implicaría trastornos renales como la insuficiencia renal crónica y aguda; obstrucción de las vías urinarias; excesiva destrucción de proteínas como en estados de fiebre, toxicidad o sépsis extensa; hemoconcentración debida generalmente a graves vómitos o diarréas; y también una alteración de la función cardíaca que reduce el flujo de sangre a través de los riñónes (8).

Estos resultados coinciden con investigaciones realizadas por Boucourt et al (29), indicando el efecto de Lactobacillus con menor nivel de urea en los grupos tratados.

En conclusión, L. plantarum $1 \mathrm{H} 1$ y L. plantarum 1 H2 adicionados en la ración de iniciación mostraron un efecto positivo en la colonización y adhesión en el tracto gastrointestinal de los lechones en la fase de precebo, así como, una respuesta positiva en su sistema inmune y mejoras en la salud al reducir los niveles de colesterol total y BUN de los animales tratados.

\section{Agradecimientos}

A la empresa Cerdos del Valle S.A. (CERVALLE), Cali, Comobia, por la financiación de esta 
investigación que constituyen los resultados parciales del Trabajo de Investigación de Tesis de Doctorado desarrollado en la Universidad del Valle. A la Escuela de Ingeniería de Alimentos; al Dr. Germán Bolívar del Laboratorio de
Microbiología y Biotecnología; al Laboratorio de Microscopía Electrónica de la Universidad del Cauca y a la Dra. Sonia González. A todas personas que de una u otra manera colaboraron para el desarrollo de esta investigación.

\section{REFERENCIAS}

1. Yamamoto $M$, Sato $S$, Hemmi $H$, Sanjo $H$, Uematsu S, Kaisho T et al. Essential role for TIRAP in activation of the signalling cascade shared by TLR2 and TLR4. Natur 2002; 420: 324-329.

2. Isolauri $E$, Salminen $S$, Ouwehand $A C$. Microbial-gut interactions in health and disease. Probiotics: Best Pract Res Clin Gastroenterol 2004; 18: 299-313.

3. Gardiner GE, Casey PG, Casey G, Lynch PB, Lawlor PG, Hill C et al. Relative ability of orally administered Lactobacillus murinus to predominate and persist in the porcine gastrointestinal tract. Appl Environ Microbiol 2004; 70: 1895- 1906.

4. Pathmakanthan S, Li CK, Cowie J, Hawkey CJ. Lactobacillus plantarum 299: beneficial in vitro immunomodulation in cells extracted from inflamed human colon. J Gastroenterol Hepatol 2004; 19: 166-173.

5. Stingele F, Corthesy B, Kusy N, Porcelli SA, Kasper DL, Tzianabos AO. Zwitterionic polysaccharides stimulate $T$ cells with no preferential $\mathrm{V}$ beta usage and promote anergy, resulting in protection against experimental abscess formation. J Immunol 2004; 172: 1483-1490.

6. Inohara N, Ogura Y, Fontalba A, Gutiérrez $\mathrm{O}$, Pons $\mathrm{F}$, Crespo J et al. Host recognition of bacterial muramyl dipeptide mediated through NOD2. Implications for Crohn's disease. J Biol Chem 2003; 278: 55095512.

7. De Angelis M, Siragusa S, Caputo L, Ragni A, Burzigotti R, Gobbetti M. Survival and persistance of Lactobacillus plantarum 4.1 and Lactobacillus reuteri 357 in the gastrointestinal tract of pigs. J Vet Microbiol 2007; 123: 133-144.
8. Swindle MM, Smith A. Swine in Biomedical Research. En: Reuter JD, Suckow MA. Sourcebook of Models for Biomedical Research. New York: Humana Press; 2003. p. 233-239.

9. Cholesterol HDL Precipitating Reagent. [Fecha de acceso 10 de febrero de 2010]. Disponible en: http://www.biosimex. com.mx/pdf/insertos/QUIMICA\%20 CLINICA/11648c.pdf

10. National Cholesterol Education Program Expert Panel. Third report of the National Cholesterol Education Program (NCEP): Expert Panel on Detection, Evaluation, and Treatment of High Blood Cholesterol in Adults (ATP III). Bethesda: National Heart, Lung and Blood Institute; 2001.

11. Brizuela MA. Selección de cepas de bacterias ácido lácticas para la obtención de un preparado con propiedades probióticas y su evaluación en cerdos. [Tesis de Doctorado]. La Habana: Instituto Cubano de los Derivados de la Caña de Azúcar; 2003.

12. Zhang W, Azevedo M, Wen K, Gonzalez A, Saif L, Li G et al. Probiotic Lactobacillus acidophilus enhances the immunogenicity of an oral rotavirus vaccine in gnotobiotic pigs. J Vaccin 2008; 1: 3655-3661.

13. Ouwehand A, Isolauri E, Saliminen S. The role of the intestinal microflora for the development of the immune system in early childhood. Eur J Nutr 2002; 41 (1): 132-137.

14. Arribas MB. Probióticos: una nueva estrategia en la modulación del sistema inmune. [Tesis de Doctorado]. Granada: Universidad de Granada; 2009. 
15. Mare L, Wolfaardt GM, Dicks LMT. Adhesion of Lactobacillus plantarum 423 and Lactobacillus salivarius 241 to the intestinal tract of piglets, as recorded with fluorescent in situ hybridization (FISH), and production of plantaricin 423 by cells colonized to the ileum. J Appl Microbiol 2006; 100 (4): 838-845.

16. Casas I, Jonsson $\mathrm{H}$, Mollstam B y Roos S, inventores; Oficina española de Patentes y Marcas. Lactobacillus que albergan genes de agregación celular y de fijación de mucina, como vehículos de aporte de vacunas. España patente 09/039.773. 2005 Jul 16.

17. Schultz M, Veltkamp C, Dieleman LA, Grenther WB, Wyrick PB, Tonkonogy SL et al. Lactobacillus plantarum $299 \mathrm{~V}$ in the treatment and prevention of spontaneous colitis in interleukin-10-deficient mice. Inflamm Bowel Dis 2002; 8: 71-80.

18. Reuter G, Klein G, Goldberg M. Identification of probiotic cultures in food samples. Food Res Int 2002; 35 (2-3): 117-124.

19. Tizard IA. Inmunología Veterinaria. México: McGraw-Hill Interamericana; 2002.

20. Charalampopoulos D, Wang R, Pandiella $\mathrm{S}$, Webb C. Application of cereals and cereal components in functional foods: a review. Int J Food Microbiol 2002; 79(12):131-141.

21. Plevy S. The immunology of inflammatory bowel disease. Gastroenterol Clin North Am 2002; 31(1):77-92.

22. Van Niel CW, Feudtner C, Garrison MM, Christakis DA. Lactobacillus therapy for acute infectious diarrhea in children: a meta-analysis. Pediatr 2002; 109:678-84.
23 Drakes M, Blanchard T, Czinn S. Bacterial probiotic modulation of dendritic cells. Infect Immun 2004; 3299-3309.

24. Braat $H$, van den Brande J, van Tol $E$, Hommes D, Peppelenbosch $M$, van Deventer $S$. Lactobacillus rhamnosus induces peripheral hyporesponsiveness in stimulated CD4+ T cells via modulation of dendritic cell function. Am J Clin Nutr 2004; 80: 1618-1625.

25. Lim HJ, Kim SY, Lee WK. Isolation of cholesterol-lowering lactic acid bacteria from human intestine for probiotic use. J Vet Sci 2004; 5:391-395.

26. Haberer $P$, du Toit M, Dicks LMT, Ahrens F, Holzapfel WH. Effect of potentially probiotic lactobacilli on faecal enzyme activity in minipigs on a high-fat, high-cholesterol diet-a preliminary in vivo trial. Inter J Food Microbiol 2003; 87: 287-291.

27. Pino A, Dihigo E. Estudio de los indicadores morfométricos del Tracto Gastro Intestinal (TGI) de cerdos en crecimiento de preceba alimentados con un producto de actividad prebiótica. En: Segundo Congreso de Producción Animal Tropical; San José de las Lajas 26-29 Noviembre de 2007. Provincia La Habana: Instituto de Ciencia Animal; 2007. 176 p.

28. Kiebling G, Schneider ] \& Jahreis G. Lomgterm consumption of fermented dairy products over 6 months increases HDL cholesterol. Eur J Clin Nutr 2002; 56: 843.

29. Boucourt R, Savón L, Díaz J, Brizuela MA, Serrano P, Prats A et al. Efecto de la actividad probiótica de Lactobacillus rhamnosus en indicadores fisiológicos de lechones. Rev Cub Cienc Agrícol 2004; 38 (4): 411-416. 